\title{
POPULISMO PUNITIVO, OPINIÓN PÚBLICA Y LEYES PENALES EN ESPAÑA (1995-2016)
}

\section{PUNITIVE POPULISM, PUBLIC OPINION AND PENAL LAW IN SPAIN (1995-2016)}

\author{
Joan Antón-Mellón \\ Catedrático de Ciencia Política. Universidad de Barcelona \\ jantonmellon@ub.edu
}

Elisenda Antón Carbonell

Mediadora comunitaria y consultora

elisenda.anton@gmail.com

Recibido: Noviembre de 2017

Aceptado: Diciembre de 2017

Palabras clave: populismo punitivo, opinión pública, reformas penales.

Keywords: punitive populism, public opinion, penal reform.

Resumen: El presente artículo pretende desglosar la definición y contenidos del término penalístico "populismo punitivo" desde su aparición como concepto académico, explicitándose sus funciones y racionalidad sistémica. Seguidamente se describirán las implicaciones entre dicha racionalidad sistémica, los medios de comunicación de masas y la opinión pública. Se analiza igualmente cómo todo ello ha repercutido en los cambios legislativos penales que han tenido lugar en España entre 1995 y 2016.

Abstract: This article focuses in the definition and content of punitive populism since its appearance as an academic concept, making clear its functions and systemic rationality. In a second part, we will describe the implications of that systemic rationality, mass media and public opinion. We will analyze how the fore mentioned affected the legislative process and changes in Spain from 1995 to 2015.

\section{Definición, cambios sistémicos y nuevo paradigma penal}

La Sociología y Criminología Críticas anglosajonas del último decenio del siglo XX e inicios del s. XXI fueron el marco académico en el que surgió el término populismo punitivo. Concretamente fue A. Bottoms el primero en utilizarlo en su obra The Philosophy and politics of punishment and sentencing (1995), seguido por otros autores Roberts et al. (2003), Newburn y Jones (2005) y Pratt (2007). Todos ellos entendían por populismo punitivo la utilización electoralista del Derecho Penal. Acríticamente, 
determinadas élites políticas occidentales agravaban sistemáticamente las penas de los delitos para dar respuesta a las presiones de la opinión pública sin cuestionarse las causas estructurales de los delitos; sin tener en cuenta los datos empíricos de los índices de criminalidad; obviando el enorme grado de subjetividad existente en la opinión pública debido a la truculencia (económicamente interesada) de algunos medios de comunicación de masas, alcanzándose, puntualmente, situaciones de pánico moral/alarma social; y despreciando las autorizadas opiniones de los expertos en la materia. Si esas élites políticas occidentales hubieran escuchado a dichos expertos, hubieran sabido que los cambios legislativos efectuados según los criterios populistas punitivos ni reducirían los delitos ni serían la salvaguarda del consenso moral de la sociedad. Ambas cuestiones son demagógicos objetivos que se pretendían lograr en paralelo a su auténtico objetivo, ganar las elecciones: alcanzar o revalidar el poder.

Estas políticas criminalísticas se incardinan y son a la vez exponente de la hegemonía política, económica y cultural de lo que ha venido en denominarse neoliberalismo a partir de los años ochenta del pasado siglo. Su fundamentación teórico/ filosófica es el famoso aforismo de Nozick (1988): Toda redistribución es un robo que atenta contra los derechos individuales. La obra señera del primer Nozick, Anarquía, Estado y Utopía, planteaba un auténtico cambio de paradigma sistémico: si hasta los últimos decenios del siglo XX (desde 1945 hasta 1973) más democracia significaba lograr una mayor igualdad, los triunfantes criterios neoliberales (Hayek, Nozick o los economistas de la Escuela de Chicago) propugnaban que una mejor democracia era aquella en la que más se respetaran y garantizaran los derechos individuales. Ante la globalización y las profundas transformaciones socioeconómicas (paso de sociedades industriales a postindustriales) que están teniendo lugar, los valores y criterios políticos redistributivos de socialdemocrátas, liberales radicales e incluso demócratacristianos ceden el paso a la ideología de liberales conservadores doctrinarios. Obviamente se rechazan de plano las políticas redistributivas progresistas, que son la clave de bóveda de los Estados de Bienestar y de Ios Estados Sociales y Democráticos de Derecho. Este cambio de paradigma político/cultural influye en todos los ámbitos de la vida de los ciudadanos occidentales, en su forma de comprender qué está pasando y qué hacer, en su percepción y valoración de los problemas sociales y en qué hacer para resolverlos.

Garland (2001) lo explica muy bien desde la perspectiva criminalística. En las décadas posteriores al fin de la Segunda Guerra Mundial, dada la hegemonía de los valores democráticos antifascistas, los delincuentes eran vistos como individuos que podían y debían ser resocializados. Las sociedades occidentales habían abandonado las protofascistas teorías criminalísticas de la Defensa de Sociedad y dedicaban los recursos necesarios para lograr reintegrar al delincuente a la comunidad, solucionando los déficits que éste pudiera tener, ya fueran educacionales, sanitarios o laborales. En contraposición, el axioma liberal de que la sociedad es un mero agregado de individuos llega a su paroxismo antiholístico con el neoliberalismo. Nadie debe nada a nadie y lo que se consigue es para el exclusivo uso y disfrute de su legítimo propietario. No te sacrifiques por nadie, vive por tu propio interés, sentenciaba Nozick (paradójica- 
mente hijo de un conductor de tranvías de Nueva York y estudiante gracias a becas).

Volviendo a Garland, éste afirma que en materia criminal se ha pasado en las referidas fechas de un paradigma resocializador a un paradigma incapacitador. Para que este paradigma pudiera implementarse, han sido necesarios profundos cambios culturales en la sociedad: que ésta juzgue a los delincuentes como únicos culpables de su realidad y de sus actos; no se trata, por tanto, de resocializar sino de castigar. En el 2015, en una encuesta en España en la que una de las preguntas era si se estaba de acuerdo con la inclusión en el Código Penal de la nueva figura de la Prisión Perpetua Revisable, el $67 \%$ de los encuestados contestó que sí (diario El Mundo 2/04/2015); en consonancia con esta opinión, se opta, en algunos países occidentales, por reducir las partidas presupuestarias destinadas a la resocialización y construir más cárceles o inaugurar y potenciar el negocio de las cárceles privadas.

El populismo punitivo apareció, por tanto, en un contexto histórico, social y económico concreto, al modo de un conjunto de planteamientos y respuestas políticas, desde una óptica neoliberal/conservadora muy doctrinaria e hiperideologizada, a las profundas transformaciones socioeconómicas de una determinada fase de desarrollo capitalista bajo la férrea hegemonía del capital financiero internacionalizado. Al triunfar dichos planteamientos y convertirse en políticas públicas y cambios culturales en la ciudadanía, Beckett y Western (2000) afirman que se ha pasado de lograr mantener el orden social mediante el Estado Social (Welfare State) al control social (Social Control). Hecho que Simon (2007), en su obra Governing through crime, desarrolla estableciendo que se pretende encarar los problemas sociales utilizando -fundamentalmente- la legislación penal; o sea, podríamos afirmar metafóricamente, "gobernar a través del delito". Además, recordemos, las evidencias empíricas muestran que los recortes en las prestaciones de los Estados Sociales han provocado un creciente aumento de las desigualdades sociales que, a su vez, ha propiciado un aumento de los comportamientos delictivos en los sectores más desfavorecidos de la sociedad. Factores que, al producirse en una atmósfera cultural neoliberal-conservadora, refuerzan la idea de que hay reducir los delitos incrementando las penas. Individualizando los delitos y velando por los factores sociales como variables en la existencia/aumento/ disminución de la criminalidad.

La implementación de estas políticas criminalísticas causó un gran aumento de la población reclusa en Occidente. En EE.UU, ejemplo paradigmático del éxito del populismo punitivo, de 1980 a 2014 la población encarcelada se triplicó hasta la cifra de 2,217 millones en julio de 2015 -llegando a ser el 22\% de la población reclusa mundial-. En esas fechas, 1 de cada 31 ciudadanos adultos de EE.UU (con una sobrerrepresentación de la población afroamericana) estaba recluido en cárceles federales, estatales regionales o privadas; cantidad a la que hay que sumar otros 4 millones de personas que estaban sometidas a otras medidas cautelares penales (más datos sobre sistema penitenciario estadounidense en www. sentencingproject.org)

La gravedad de las consecuencias sociales del paso de sociedades rehabilitadoras a incapacitadoras (Ios delincuentes son "emprendedores fuera de la ley" que hay que apartar de la sociedad) ha ocasionado el interés académico por desvelar sus 
causas. L. Wacquant en Las cárceles de la miseria (2000) y Castigar a los pobres (2010) y M. Tonry en Thinking about crime (2004), desde una perspectiva más sociológica y politológica el primero y más jurista el segundo, analizan a fondo la racionalidad sistémica de este relevante fenómeno del populismo punitivo. Desde un enfoque más europeo, explicitando su globalización, cabe citar los estudios de Green y Rutherford, Criminal policy in transition (2000); Karstedt y Bussmann, Social Dynamics of Crime and Control (2000); Hope y Sparks, Crime, Risk and insecurity (2001); Stenson y Sullivan, Crime, Risk and Justice, (2001); Pratt et al., The new punitiveness (2005), entre otros. La aguda inteligencia de M. Pavarini (2009:74) resume de esta forma la última ratio de lo que está sucediendo: "El crecimiento de la multitud de excluidos torna políticamente irreal el proyecto de orden social a través de la inclusión."

Las motivaciones sistémicas de esta deriva occidental autoritaria/penal tienen su origen en las mencionadas transformaciones estructurales del paso de sociedades de sistema de producción fordista a post-fordista (Garland, 2005; Letamendia, 2009; Pavarini, 2009; Harvey, 2008). Como exponíamos en otro trabajo anterior (Antón-Mellón et alia, 2017: 7), globalización, neoliberalismo, reconversión del sistema productivo y reorganización de la fuerza de trabajo son diferentes aspectos de un mismo proceso: una nueva fase del capitalismo hegemonizada por el sistema financiero y acelerados sus efectos por los ciclos económicos recesivos (Zolo, 2006). Teniendo como revelador resultado el gradual recorte de los beneficios sociales, el incremento de las rentas del capital a costa de las rentas del trabajo (Fontana, 2011; Piketty, 2014) y el constante aumento de la pobreza y las desigualdades.
La respuesta neoconservadora, dadas las consecuencias sociales de estos procesos macroeconómicos, ha sido criminalizar la pobreza, individualizar los problemas sociales y adoptar estrategias mixtificadoras y represivas. El neoliberalismo/neoconservadurismo, pues, enfatiza la responsabilidad individual del delito (la comisión de un delito depende de uno mismo) y arrincona las causas generadoras de la delincuencia, actuando únicamente en la penalización del acto. El populismo punitivo es, por tanto y al mismo tiempo, uno de los recursos utilizados como punto de inserción entre cambios socioeconómicos estructurales, hegemonía ideológica neoliberal, derecho y políticas públicas. Como afirma el sociólogo criminalista J. Young (2003: 5): "En este último mundo moderno la exclusión se produce en tres niveles: la exclusión económica en los mercados de trabajo, la exclusión social entre la gente de la sociedad civil y las siempre expansivas actividades excluyentes del sistema de justicia criminal y la seguridad privada".

El mencionado L. Wacquant expone en varias de sus obras referidas que el populismo punitivo es uno de los factores sustentadores clave de la racionalidad sistémica del neoliberalismo, e incluso lo analiza no como una consecuencia de éste, sino como una imperiosa necesidad estructural para su implementación, desarrollo y supervivencia. Se trata de consolidar un determinado proyecto político para un mundo globalizado y transnacional. Gobernado, indirectamente, por una tecnoestructura que ha edificado, con el auxilio entusiasta de élites políticas e instituciones reguladoras tipo FMI, unas concretas relaciones económicas y políticas entre mercados, Estados y ciudadanía. Relaciones en las que los factores decisivos son aquellos que permiten su reproducción y el mantenimiento de unas tasas 
de beneficio de las inversiones efectuadas por las élites dirigentes y su hegemonía política y cultural.

Las políticas criminalísticas incapacitadoras sólo pueden entenderse si nuestros anteriores análisis aciertan en su imbricación funcional con otras lógicas sistémicas, previamente referidas, con las cuales se incardinan: razones económicas -desregulación económica, reducción (en la medida de lo políticamente posible) de los beneficios y ayudas sociales, aumento de los beneficios del capital en detrimento de los del trabajo etc.-; razones culturales -potenciamiento del hiperindividualismo y el hipermaterialismo, autorresponsabilidad y cultura del emprendimiento, criminalización de la pobreza, enaltecimiento político de las víctimas etc.- y razones penales -populismo punitivo en creciente expansión-.

Para Larrauri (2006), concluyendo este apartado, el aumento de la población reclusa occidental es, también, consecuencia, método y exponente del neoliberalismo/ neoconservadurismo. Según su análisis, los factores económicos, políticos, sociales, culturales y penales se entrelazan sistémicamente. Recortes y/o supresión de ayudas sociales; reconversiones del sistema productivo y gradual aumento de las desigualdades, pobreza en aumento e inestabilidad e inseguridad laboral; deslocalización de empresas con vistas a reducir los costes de producción y aumentar los beneficios. Aumento creciente de unos sectores de la población excluidos del sistema, en término anglosajón underclass, según la terminología utilizada por algunos países latinoamericanos (p. e. Colombia o Costa Rica) desechables por razón de su pertenencia a minorías étnicas, género, edad o clase social. Nueva visión del delincuente como exclusivo culpable de sus actos individuales sin inqui- rir en los factores sociales que inciden en actitudes y comportamientos. Conduciendo todo ello, concluye, a un determinado criterio y modelo político: estas sociedades sólo pueden ser gobernadas eficazmente mediante un sistema punitivo muy fuerte y desarrollado. El último recurso social que debería utilizarse, el Código Penal, se convierte en la punta de lanza de un sistema incapacitador de control social que, gradualmente, va abandonando sus anteriores criterios democráticos rehabilitadores.

\section{Características del populismo punitivo}

El conjunto de académicos que han investigado los componentes y características del populismo punitivo coinciden en destacar tres factores que constituyen el núcleo de su lógica argumentativa o narrativa: el cambio del papel atribuido a la cárcel, según criterios de substitución del paradigma resocializador al paradigma incapacitador; colocar en primer plano los sentimientos y opiniones de las víctimas y, por último, la politización y utilización electoralista de las percepciones subjetivas ciudadanas de la inseguridad vehiculadas por los medios de comunicación de masas sensacionalistas.

Garland (2001), incluso, establece un modelo teórico y desglosa un conjunto de doce indicadores que nos pueden permitir contrastar, medir y valorar el grado de implementación del populismo punitivo en una sociedad: el cuestionamiento de los criterios resocializadores; el incremento de las sanciones punitivas y degradantes; la magnificación de las víctimas; el cambio de la cultura punitiva en la sociedad, predominando el castigo/venganza sobre la 
resocialización; la anteposición de criterios de protección pública a otras variables; la politización y electoralismo de las cuestiones criminológicas; la visión de las prisiones como medio casi exclusivo para lograr la incapacitación de los delincuentes; la variación del pensamiento criminológico en el sentido de juzgar la delincuencia como actos racionales; el reconocimiento de las limitaciones del Estado para lograr el control de los delitos y que la responsabilidad del delito debe recaer en la sociedad y en el propio delincuente; la compaginación de los ámbitos públicos y privados en las tareas de prevención y control del delito; la introducción de criterios exclusivamente económicos de coste-beneficio en materia penal en lugar de juicios individualizados o criterios normativos y la exposición discursiva reiterada de crisis que necesita la implementación de medidas eficaces. De aquellos tres factores más relevantes, articulados con los anteriores indicadores, es necesario ampliar analíticamente el destacado papel de la cárcel, la cuestión de las víctimas y la politización y uso electoralista demagógico de la percepción social de la inseguridad.

Sobre las prisiones y su cambio de funcionalidad y cultura criminalística referencial, Stiglitz (2012), por reiterar otra autorizada opinión académica, subraya que el neoliberalismo hegemónico establece que las instituciones penitenciarias son, de facto, el instrumento de control social "necesario" ante el constante aumento de las desigualdades, la pobreza y la exclusión social en Occidente. Esta "solución" requiere de un cambio en la visión cultural-social del delincuente, como expone Diéz Ripollés (2004: 29): “El delincuente deja de ser un ser socialmente desfavorecido y marginado al que la sociedad estaba obligada a prestar ayuda, para ser visto como un ser que persigue intereses egoístas e inmorales, a costa de los legítimos intereses de los demás." La visión del homo economicus se traslada al delincuente, y a éste se le juzga socialmente como un ser libre y autónomo (no como un marginado con déficits y carencias sociales) que obra de un modo perfectamente racional, escogiendo libremente sus opciones, maximizando sus intereses y haciendo un buen uso de las oportunidades que se le presentan en el mercado.

Por lo que se refiere al creciente papel de las víctimas, se ha privilegiado la opinión justiciera de éstas en la adopción de políticas públicas y en la legislación penal. Los crímenes truculentos producen víctimas y alarma social y son amplificados por unos medios de comunicación de masas ávidos de ganar cuotas de audiencia que se plasmarán en suculentos beneficios económicos. Lo cual produce un incremento de la percepción social subjetiva de inseguridad a la que las élites dirigentes deben dar respuesta, máxime en situaciones puntuales de pánico moral. Aumentan las asociaciones de víctimas (terrorismo, tráfico, mujeres maltratadas etc.) que se organizan como auténticos lobbys para lograr sus reivindicaciones y objetivos justicieros, protagonizando y parcializando los debates criminalísticos y dejando en un plano subalterno irrelevante la opinión de los expertos, los datos objetivos e incluso el bienestar del conjunto de la sociedad. Como expone Diez Ripollés (2004: 29): "La relación entre víctima y delincuente ha entrado en un juego de suma-cero: cualquier ganancia por parte del delincuente, por ejemplo, en garantías procesales o en beneficios penitenciarios, supone una pérdida para las víctimas, que lo ven como un agravio o una forma de eludir las consecuencias de la condena". Las víctimas 
y las asociaciones de víctimas presionan a las Administraciones Públicas y los medios de comunicación de masas se hacen eco amplificador de crímenes, investigaciones, juicios y actuaciones políticas de los diferentes actores sociales. Como es obvio, los partidos políticos no son ajenos a estos cambios y realidades de la opinión pública, de ahí que articulen (unos más que otros) discursos y cambios legislativos para satisfacer las demandas existentes y derrotar electoralmente a sus adversarios.

Como muestra, veamos el programa electoral que el Partido Popular (PP) presentó en las elecciones del 2008. Éste incorporaba un apartado acerca de: "Una justicia al servicio del ciudadano y protectora de las víctimas" y se indicaba: "Reforzaremos el papel de las víctimas y sus derechos, reformando el Código Penal, la Ley de Enjuiciamiento Criminal y la Ley General Penitenciaria, incorporando nuevos derechos para las víctimas y un mayor protagonismo procesal, de forma que sean necesariamente oídas antes de acordar la libertad condicional de cualquier condenado por delitos graves contra las personas" (Partido Popular 2008: 50).

Finalmente, en este apartado, respecto a la politización y electoralismo demagógico de las cuestiones relativas a la inseguridad criminal, reiteremos cuáles son los objetivos partidistas: minar las expectativas electorales de los adversarios e incrementar las propias. Académicos estudiosos del tema que nos ocupa han llegado a idénticas conclusiones. Fuentes Osorio (2005); Luís Pérez-Neto (2010) y GarcíaBorés (2015) afirman que los réditos que logran los partidos políticos adoptando la lógica argumentativa y los criterios populistas punitivos son: satisfacer las demandas de la opinión pública, dar la sensación política de respuesta inmediata y eficaz a los problemas sociales, estupefaciente psicológico para las ansiedades sociales y, finalmente, no tener que enfrentarse con las causas sistémicas de los problemas.

\section{El encarcelamiento como herramienta principal del populismo punitivo en España (1995-2016)}

\section{3.l. Etapas y evolución del sistema penitenciario español (1995-2016)}

Siguiendo los análisis de Brandariz (2016) y Antón-Mellón et alia (2016) estableceremos tres etapas diferenciadas en el sistema penitenciario español de las últimas décadas: una etapa de transición (1995-2000); una etapa de expansión (2000-2010) y una etapa de recesión (2010-2016).

En la primera etapa de transición, de 1995 al 2000, tienen lugar tres importantes transformaciones que constituyeron los fundamentos de unas nuevas etapas en política carcelaria. La primera fue la aprobación del llamado "Código Penal de la Democracia" (LO 10/1995), sustituto de la legislación penal de la dictadura (1944/1973). En dicho Código, se introdujeron nuevas penas como el arresto de fin de semana o los trabajos en beneficio de la comunidad, el reforzamiento de la suspensión condicional de las penas privativas de libertad o la implantación de la institución de la sustitución de la prisión. Sin embargo, su resultado fue más severo en la práctica que su antecesor (a pesar de que sus consecuencias se manifes- 
taron en la siguiente etapa), a raíz de la derogación de la institución de la redención de penas por el trabajo (art. 10 CP 1944/1973).

La segunda relevante transformación se relacionaba con el cambio en los perfiles mayoritarios de la población reclusa. A mediados de la década de los 90 del pasado siglo finaliza el denominado ciclo de la heroína: el consumo de esa droga por miles de jóvenes toxicómanos, a menudo politoxicómanos, había llenado las cárceles de drogadictos y la pequeña delincuencia estaba intrínsecamente unida a devastadoras y graves adicciones y delitos contra la salud pública. El consumo de heroína disminuye a causa de la aparición de nuevas drogas más baratas, el descenso de precios de otros estupefacientes y la información existente sobre los riesgos de su consumo reiterado. Como consecuencia, en las cárceles españolas se diversifican los perfiles de los reclusos.

La tercera transformación reseñable, también producida a mediados de los 90, consiste en la política de edificación de nuevos establecimientos penitenciarios, sustitutos de las clásicas cárceles radiales prototípicas de etapas anteriores de modelo panóptico. Estas nuevas cárceles se diseñan a partir de unidades modulares, denominadas Centros-Tipo, donde se logra mejorar altamente las condiciones de habitabilidad, aliviar los problemas derivados de la sobreocupación y racionalizar las condiciones de seguridad de reclusos y funcionarios. Sin embargo los inconvenientes fueron que la estructura modular de los Centros-Tipo restringía las relaciones personales y de circulación de los presos, los contactos con el exterior y el régimen de visitas, dados los lugares lejanos a los centros urbanos en los que dichos centros se construyeron. En paralelo, se construyeron los CIS (Centros de Inserción Social), de régimen abierto: éstos se diseñaron para el cumplimiento alternativo del encierro carcelario y, en una primera etapa, para los arrestos de fin de semana. En dichos centros se separaba a los reclusos de segundo y tercer grado y, dado que sus criterios teóricos respondían a una lógica reintegradora y resocializadora, estaban situados en zonas urbanas.

Cabe reseñar que en esta etapa los grandes partidos que se turnan en el poder (PSOE y PP) comparten algunos elementos teóricos incapacitadores en materia criminal, debido en parte a la problemática del terrorismo etarra que se asocia a factores de seguridad ciudadana. El análisis de los discursos electorales de los comicios de 1996 y 2000 así lo evidencia, aunque persiste una retórica garantista. En esos comicios sólo IU apuesta por un modelo penitenciario terapéutico y resocializador, en las antípodas de los criterios populistas punitivos incapacitadores.

La segunda etapa de expansión, de 2000 a 2010, se caracteriza por el fin definitivo del ciclo de la heroína y la sustitución mayoritaria del drogadicto marginado por población reclusa inmigrante, fruto de la llegada masiva de extranjeros a España debido al gran crecimiento económico de esos años, reflejado en el hecho de que en 2009 la población reclusa extranjera era el 35,7\% del total. Se continúa con la política de construcción de nuevos centros penitenciarios, inaugurándose 6 Centros-Tipo y 22 centros de reinserción social. Fueron necesarios más centros, ya que la población reclusa en España aumentaba gradualmente, pues la aplicación del Código Penal de 1995 había causado un proceso de aumento de la 
punición tanto en términos extensivos (incremento de los delitos) como extensivos (duración de las penas). Por ejemplo, la duración media de encarcelación en el año 2000 era de 13,1 meses y en 2010 era de 19,3 meses; un aumento del $47,3 \%$. Dichos criterios penales se intensificaron a partir de 2003 con la administración del PP, cuando se profundizó en la expansión intensiva -ampliación del volumen de conductas penalizables, LO 15/2003- y la expansión extensiva -crecimiento sostenido de la duración efectiva de los tiempos de cumplimiento de la pena, LO 7/2003-.

El Gobierno del PP, presidido por José $\mathrm{M}^{\mathrm{a}}$ Aznar, justificó del 2000 al 2004 su política criminal de endurecimiento progresivo por el terrorismo etarra y la pequeña delincuencia urbana, que había aumentado la percepción subjetiva de inseguridad en las grandes urbes. Se incrementaron las penas por terrorismo hasta extremos que rozaban la inconstitucionalidad, como la Ley Parot, se restringió el acceso al tercer grado penitenciario y a la libertad condicional y se castigaron con mayor dureza las penas por delitos menores: en estos años se aprobaron más de 15 reformas penales, siempre desde una óptica incapacitadora y populista punitiva. La mayoría absoluta del PP de esos años garantizaba la aprobación, hubiera o no debate parlamentario cuestionador, de los mencionados textos legislativos.

Echando más leña al fuego, la oposición parlamentaria del PSOE, liderada por José Luís Rodríguez Zapatero, vio una oportunidad de desgastar políticamente al PP denunciando, reiteradamente, el aumento de la criminalidad, factor refrendado por los barómetros de opinión del CIS de 2002 que reflejaban que la inseguridad en España había pasado de estar en el décimo lugar de problemas prioritarios al tercero. De esta forma los debates parlamentarios entre los dos partidos mayoritarios polemizaban en torno a cuánto se debían incrementar las penas, y sus líderes políticos recibían a los representantes de las asociaciones de víctimas y a los familiares de crímenes truculentos, muy atentos políticamente a una opinión pública traumatizada por los atentados etarras y determinados crímenes de índole sexual, profusamente publicitados por los medios de comunicación de masas sensacionalistas.

En la tercera etapa de recesión (20102016) las gravísimas consecuencias socioeconómicas de la crisis que se había iniciado en 2008 inciden de lleno en las decisiones que se adoptan en materia penal. Máxime si tenemos presente que se hacen recaer los costes de la crisis sobre los sectores más desfavorecidos y vulnerables de la sociedad. La reforma laboral legaliza una gran disminución de la capacidad adquisitiva de los salarios mediante diferentes medios: abaratamiento de los despidos, precarización laboral, congelación de sueldos, aumento del paro, menos ingresos y más gastos. La fase expansiva anterior debe ser corregida por nuevas reformas legislativas como la LO 5/2010 para la reforma del Código Penal (promovida por la administración PSOE), por la cual se reducían las penas por múltiples delitos, por ejemplo, en delitos contra la salud pública (drogas, arts. 368 y ss. del Código Penal). En este período la población reclusa española alcanza la cifra de 76.951 reclusos, la más alta desde los años 50 del pasado siglo. Los recortes presupuestarios determinan que sea necesaria la disminución de la población encarcelada. Entre mayo de 2010 y octubre de 2013 los presos se reducen en un $12 \%$. 


\subsection{Síntesis conclusiva de las tres etapas sobre criterios penalísticos populistas punitivos y datos empíricos en España}

A nivel de políticas penitenciarias, tanto en Occidente como en España, en el período analizado el recurso de prisión se convierte en el pilar central de las políticas de corte populista punitivo; en España, de manera paradigmática en forma y fondo, a través de la ampliación de los supuestos legales que posibilitan la adopción de la pena de pérdida de libertad - LO 13/2003-. Todo ello conlleva el aumento progresivo ya citado de la población reclusa, debido a la creciente "solución" de cárcel que provoca el populismo punitivo a los problemas sociales de transformación sistémica, como previamente vimos. Por todo ello, se deduce que la progresión del número de personas privadas de libertad en un país es un indicador de causa y efecto importante a la hora de calibrar la implantación del populismo penal. Si centramos el análisis en el Estado español, encontramos que la ratio de población reclusa se ha doblado entre la década de los 80 hasta la primera de los 2000. Tal y como apunta Díez Ripollés (2006), en la década de los 2000 la tasa comparada de población en prisión en España se situaba por encima de la media europea, sólo superada por Inglaterra/Gales y Polonia; en el año 2009, España se situó como el país europeo con la mayor tasa de encarcelamiento (excluyendo a Suiza y Luxemburgo). El informe 2015 de ROSEP, el Observatorio del Entorno Penitenciario de la Red de Organizaciones Sociales del Entorno Penitenciario indica que la tasa de encarcelamiento actual en España se sitúa un $32 \%$ por encima de la media de los países europeos, habiendo en España el doble de reclusos que en Finlandia y Suecia.

Según el informe de la ACAIP (Agrupación de los Cuerpos de la Administración de Instituciones Penitenciarias) de 2010, la tasa de población penitenciaria en España ha experimentado un incremento incesante desde el año 1996, acelerándose a partir del siglo XXI y llegando a su punto más álgido en 2009 (76.951 encarcelados), año a partir del cual inició un descenso que se mantiene hasta la actualidad. Como apuntan García-Borés y Rivera (2016), en 2010 la cifra total de reclusos había disminuido a 73.929, menos del 0,5\% respecto al año anterior; en 2015 ésta cifra había pasado a 61.614 reclusos. En otras palabras, del 2009 a 2015 la población reclusa total había disminuido un 19\%. La tasa de encarcelamiento por 100.000 habitantes ha bajado progresivamente de 161 en 2010 a 133 en 2015. Lo mismo sucede con el porcentaje de extranjeros en prisión, que contaba un 35,6\% en 2010 y se situaba en el 29,0\% en el 2015. Contrariamente, el índice AROPE (pobreza y riesgo de exclusión social, por porcentaje de habitantes) ha aumentado progresivamente a un ritmo similar a la disminución del número de reclusos (26,1\% en 2010 y 28,6\% en 2015). El informe 2015 de ROSEP, antes mencionado, indica también que la tasa de delito española se sitúa un 27\% por debajo del promedio de la Europa de los 15 (Alemania, Austria, Bélgica, Dinamarca, Finlandia, España, Francia, Portugal, Grecia, Irlanda, Italia, Luxemburgo, Países Bajos, Reino Unido y Suecia), así como que el país ocupa el tercer puesto en el ránking de países con mayor seguridad. En la misma línea, el informe expone que la media de las condenas en España es de 18 meses, mientras que en el conjunto de Europa es de 7,1. 
Actualmente, según datos del Ministerio del Interior de junio de 2017, la población reclusa total es de 60.647 personas, siendo un $92,44 \%$ hombres y el $7,56 \%$ restante mujeres. Del total, un $28,17 \%$ son de nacionalidad extranjera. Sin embargo, a pesar de los datos relativamente buenos en cuanto a seguridad y número de delitos, la tasa de encarcelamiento sigue siendo alta, llegando a multiplicarse por 8 en los últimos 40 años. El mencionado informe ROSEP (2015) indica también que si España tuviera una tasa de encarcelamiento acorde a su tasa de criminalidad y a la media europea, habría una población penitenciaria de aproximadamente la mitad de la cifra de la población actual.

Ahora bien, y aquí entra en juego la otra variable central del presente artículo, estas cifras de baja delincuencia contrastan con el inagotable aumento de la atención mediática morbosa que despierta la criminalidad a través de los medios de comunicación y redes sociales, las cuales actúan como altavoces del miedo, la sensación de inseguridad y el pánico moral. En otras palabras, existe una falta absoluta de correspondencia entre el incremento de dicha atención y preocupación con la evolución de las tasas de criminalidad en España (Díez-Ripollès, 2006).

\section{Opinión Pública y leyes penales en España (1995- 2016)}

Entre los años 2000- 2004, como vimos, tuvieron lugar una serie de reformas penales punitivas que terminaron de desvirtuar el carácter rehabilitador del Código Penal español de 1995 mediante una expansión extensiva de las conductas penadas y de un crecimiento sostenido de la duración efectiva de los tiempos de cumplimiento (LO 15/2003 y LO 7/2003). Así, el apodado "Código Penal de la Democracia" de 1995 se vio endurecido mediante diversas reformas penales que se aprobaron en la VII legislatura española, bajo la presidencia de José María Aznar y con la referida mayoría absoluta del Partido Popular tanto en el Congreso (183 diputados) como en el Senado (121 senadores). Es en este quinquenio cuando se certifica la deriva punitiva del derecho penal español, como señala García Arán (2008: 44), en el que los medios de comunicación han sido un factor coadyuvante al contribuir a legitimar la necesidad de endurecer las penas.

Es a través del tratamiento mediático que los medios de comunicación realizan de los sucesos violentos acontecidos en los últimos años por lo que el populismo punitivo avanza en su influencia: las decisiones políticas en materia penal están estrechamente vinculadas con los sucesos desviados que ocurren en una sociedad y el eco y tratamiento que se hace de su cobertura mediática ${ }^{1}$. Este hecho terminó originando el denominado "Derecho Penal Simbólico", en el que el derecho penal responde a una supuesta demanda de seguridad con el endurecimiento de las penas con el fin de calmar los ánimos de la opinión pública (Pozuelo, 2013: 86). A ello debe añadírsele un contexto de desafección política y pérdida de confianza en los políticos, que hace que la acción política en materia penal sirva para reforzar el poder y la legitimidad de los políticos, poniendo de manifiesto que se preocupan por los problemas del pueblo.

1. Una versión más desarrollada de este apartado en Antón-Mellón et alia (2015). 
Esta deriva punitiva del sistema penal coincidió también en España con una época de inseguridad generalizada, recogida por los barómetros de opinión del CIS de dicho año, en los que se mostraba la inseguridad ciudadana dentro de los principales problemas percibidos por la población, después del paro y el terrorismo y antes que la inmigración y las drogas, situándose en los dos años anteriores en el décimo lugar (Sáez, 2002: 3).

Con el propósito de descifrar el impacto de los medios de comunicación en la fijación de temas electorales en la agenda pública, McCombs y Shaw, en su estudio de 1972, dieron forma a la Teoría del agenda-setting, la cual demostró, en el transcurso de su estudio en torno a la campaña presidencial de 1968 en Chapel Hill (Carolina del Norte), que había una gran correlación entre los temas presentados por los medios y los temas que los ciudadanos señalaron como más importantes (McCombs y Shaw, 1972). Así, si bien McCombs y Shaw acuñaron el término de agenda-setting, dicha idea cuenta con antecedentes importantes entre los que se cuenta a Lippmann y su obra Public Opinion (Lippmann, 1922). La Teoría de la agenda-setting hace referencia al poder de que disponen los medios de comunicación para situar un determinado tema en el debate público, convirtiéndolo en un asunto de interés nacional, independientemente de la importancia intrínseca de dicho tema (Varona, 2011: 3). En este sentido, McCombs (2006: 135) señala que es una "teoría sobre la transferencia de relevancia de las imágenes del mundo que dan los medios de comunicación a las imágenes de nuestra cabeza". Por tanto, estamos ante la función señalizadora de las noticias que apuntaba el sociólogo estadounidense Robert Park (Mc-
Combs, 2006: 24). En otras palabras, Ios medios de comunicación, al tener la capacidad de seleccionar, presentar y plantear sus noticias, terminan determinando la agenda pública y, por ende, aquello que es objeto de debate público (García Aran y Botella, 2008: 25). Así, los medios de comunicación imponen los temas más discutidos en la sociedad, fijando el calendario de los hechos sociales, seleccionando lo que es y lo que no es importante. Las sucesivas aplicaciones de esta teoría han evidenciado su eficacia como instrumento teórico-metodológico para analizar la capacidad de influencia y poder de los medios de comunicación por medio del priming y del framing; es decir, la elección de aquellos acontecimientos que serán noticia y la reinterpretación y encuadre que terminará en opinión pública. Es tan relevante qué noticias aparecen en la prensa como la manera en que son tratadas y presentadas a la sociedad; en otras palabras, las personas no sólo reciben información a través de los medios de comunicación, sino que aprenden qué temas o asuntos deben considerar prioritarios y qué énfasis les deben de dar. Por tanto, las personas perciben el mundo a través de lo que los medios le cuentan y cómo se lo cuentan, Ilegando el público a elaborar sus propias opiniones a raíz de lo recibido.

No obstante, los efectos que ejercen los medios de comunicación están supeditados a las experiencias de la audiencia sobre temas específicos. En este sentido, Soto (2005: 3) señala que la imagen que un ciudadano cualquiera puede componerse sobre la criminalidad en su país depende, en primer lugar, de su propia experiencia como víctima o de la de sus allegados, y, en segundo lugar, se convierten en fuente principal las noticias que difunden los medios en relación con la delin- 
cuencia, además del mero rumor sobre la experiencia de otros. De modo que las olas de criminalidad que impulsan los medios suelen ejercer una gran influencia en la ciudadanía, sobre todo en aquellos que no tienen experiencia directa en este campo.

Un buen ejemplo de estos dos niveles de agenda-setting y de su influencia en la inseguridad ciudadana española lo encontramos en el trabajo de Soto referido, en el que pone de manifiesto, mediante un análisis cualitativo del diario El País, cómo las noticias de delincuencia, en el periodo 2001 a 2003, pasan de un promedio mensual de treinta y siete a un promedio mensual de sesenta y tres. Dichas noticias, más de la mitad, son de sucesos que copan muchos artículos de opinión y reportajes. Los delitos que contaban con mayor cobertura informativa son, sobre todo, los homicidios y asesinatos (30,57\%), seguidos de las lesiones, delitos contra la libertad sexual, el robo y desordenes públicos. El $71,87 \%$ de las noticias sobre la delincuencia se encontraban en la parte nacional (España) y solían situarse en las primeras páginas. Además, el $45,51 \%$ de las noticias contaba con apoyo gráfico (ilustraciones, fotografías, diagramas, representaciones estadísticas, ... y y la mayor parte de los titulares sobre delincuencia violenta tenía un marcado tono dramático.

Así, con la expansión de los medios de comunicación de masas desde principios del siglo XX, dichos medios han sido conscientes de la atracción que ejercen las noticias sobre delitos (Barata, 2003), permitiéndoles emplear géneros narrativos muy interesantes. En los relatos criminales, la audiencia espera una historia con un principio y un final, que permita hacer un discurso dramático y emotivo, creando una visión simplista y escasamente me- ditada, pero que a la vez capta y retiene la atención del lector. Varona (2011: 15) afirma que "lo criminal es mediático por naturaleza", así que no es sorprendente el tratamiento destacado que ofrecen los medios de comunicación a la delincuencia o sucesos desviados. En las crónicas periodísticas suele imperar lo negativo, pues las malas noticias sobre delincuencia tienen reservado un lugar privilegiado en los medios de comunicación. Así, cuando las noticias sobre la delincuencia alcanzan los medios de comunicación lo suelen hacer bajo la lógica de la problematización o de la alarma. Apuntan a un aumento preocupante de la delincuencia, agravado por la ineficacia policial o más frecuentemente del aparato judicial penal. Por eso, no es de extrañar que las noticias sobre delincuencia que copan la información sean aquéllas en las que predomina la violencia y el dramatismo, inflándose con ello artificialmente la magnitud del problema real de la delincuencia (Varona, 2011:18). Barata (1998) afirma que hay elementos para sostener que los medios de comunicación construyen su propio discurso del delito, que en ocasiones tiene poco que ver con la realidad social.

En 1988, Rogers y Dearing afirman que la Teoría de la agenda-setting hace referencia a la compleja interrelación que existe entre las tres agendas (mediática, pública y política). En España, por ejemplo, el detonante del aumento de las noticias sobre delincuencia e inseguridad ciudadana fue un repunte estadístico sobre la tasa de delincuencia española, aprovechado por el Partido Socialista Obrero Español (PSOE) -principal partido de la oposicióncomo estrategia política para debilitar al $\mathrm{PP}$, que, como anunciábamos al principio, gozaba de mayoría absoluta. 
Un buen ejemplo práctico lo encontramos en el caso de la menor Mari Luz Cortés, de tan sólo 5 años, que fue secuestrada, abusada sexualmente y asesinada en la capital Onubense el 13 de enero de 2008 por un pederasta. Los medios de comunicación denominaron a este suceso violento "el caso que puso al descubierto las deficiencias de un sistema judicial lento y obsoleto", ya que se descubrió que el agresor había abusado de la niña de sólo 5 años en la primavera de 1988, y en 2002 fue condenado por estos abusos sexuales, pero consiguió eludir la sentencia, ya que la recurrió en varias ocasiones. Así, pudo seguir libre y sin vigilancia durante varios años. Finalmente, fue condenado a 22 años de prisión por el asesinato y abuso sexual de Mari Luz Cortés. Este caso tuvo una gran repercusión mediática, de ahí que el caso fuera juzgado por un tribunal profesional. La sociedad se movilizó contra la "pasividad" y la "inutilidad" de la justicia, que permitió a un pederasta estar en la calle a pesar de sus condenas.

En este contexto, el padre de Mari Luz Cortés, Juan José Cortés, en unas declaraciones al diario El Mundo, el 30 de marzo de 2008, acusó del asesinato de su hija al propio Presidente del Gobierno, por aquel entonces José Luis Rodríguez Zapatero, le exigió responsabilidades al Gobierno y le hizo llegar su propuesta de instaurar en territorio español la cadena perpetua. En respuesta, el Gobierno de José Luis Rodríguez Zapatero se mostró en contra de la cadena perpetua, ya que chocaba con la Constitución, pero le ofreció como solución crear un registro de pederastas que permitiera controlarlos. Años más tarde, en la justificación que el Partido Popular (PP) redactó en la presentación de una propuesta para endurecer el Código Penal en relación con los delitos de abusos sexuales a menores (posteriormente plasmada en la reforma del Código Penal en la LO 5/2010), encontramos una alusión al caso de Mari Luz Cortés.

Por otro lado, una de las características del populismo punitivo que se manifiesta de forma más directa en los medios de comunicación es el victimismo, lo que los autores han denominado el "retorno de la víctima", analizado en apartados anteriores. En este aspecto, los medios de comunicación han jugado un papel importante. Como recoge Pozuelo (2013: 87) la situación de las víctimas de delitos violentos "es con frecuencia explotada de forma morbosa por los medios de comunicación". Las noticias que narran el sufrimiento de las víctimas provocan, lógicamente, la empatía del público y como consecuencia, para paliar el sufrimiento de la víctima, éste demanda endurecer la ley penal. Los políticos, como son conscientes de su grado de responsabilidad en esta materia y de los réditos electorales que obtendrán de seguir esta demanda popular, responden endureciendo las penas, sin apenas reflexionar si la ley penal tiene una adecuada o eficaz respuesta a la problemática planteada.

La sociedad española ha experimentado en los últimos años varios sucesos violentos que han creado alarma social, producto del tratamiento informativo de los medios de comunicación. Como señala Landrove (2009: 65): "La alarma social es social porque es pública y es publicitada por unos medios de comunicación que, además, la retroalimentan, condicionando así la percepción de todo un colectivo sobre la inseguridad ciudadana; en suma, la alarma social se produce cuando los medios de comunicación dicen que se ha producido". En esta misma línea, Maqueda (2003: 6) añade 
que "la representación sesgada de la realidad que los medios de comunicación ofrecen a través de esa permanente dramatización de la amenaza atribuida a la delincuencia refuerza el sentimiento de alarma social, acrecentando la sensación de inseguridad". Esto ha producido lo que se ha denominado una legislación "a golpe de telediario" o "a golpe de escándalo". El sentimiento de inseguridad, como sostiene Kessler (2009), es la sensación de indefensión que los individuos sienten ante una amenaza aleatoria. Por tanto, creer que se puede ser víctima de un delito genera malestar y sensación de impotencia. Cuando la inseguridad individual se convierte en colectiva, estamos delante del "pánico moral», término acuñado por Stanley Cohen en 1972.

\section{A modo de conclusión}

El populismo punitivo es un pilar estructural de un modelo socioeconómico neoliberal/neoconservador hegemónico en los últimos decenios del siglo XX y primeros del XXI. Consiste en sustituir los criterios conformadores de los Estados de Bienestar por otros denominados de Control Social: politizando las leyes penales, criminalizando la pobreza y desarrollando una nueva cultura criminalística por la cual se abandonan los ideales resocializadores y se cambian por planteamientos incapacitadores. Se deja de intentar solucionar los déficits del delincuente como medio de reinsertarlo en la sociedad. No se escucha a los victimarios, pero sí a las víctimas, y éstas pasan a jugar un papel relevante en la revisión de los planteamientos penales. Las víctimas se convierten en portavoces autorizados de la opinión pública. Una opinión pública en la que los medios de comunicación de masas sensacionalistas han ejercido un papel relevante, buscando incrementar sus beneficios con un tratamiento morboso de las noticias de crímenes especialmente terribles.

Finalmente hemos constatado cómo el estudio de la influencia de la opinión pública en los planteamientos teóricos de las reformas penales pone de relieve que, ante unos singulares sucesos criminalísticos, determinados decisores políticos han utilizado demagógicamente el Derecho Penal buscando réditos electorales y eludiendo el análisis de los factores estructurales y sistémicos que subyacen a todo acto criminal individual. Todo ello, en detrimento de los límites normativos de los regímenes políticos liberales, de los ideales resocializadores de los Estados de Bienestar y contradiciendo los objetivos democráticos avanzados de los Estados Sociales y Democráticos de Derecho de abolición gradual de los privilegios y profundización de la democracia.

Además, en un contexto de desafección política y pérdida de popularidad de nuestros representantes políticos, éstos encuentran en el Derecho Penal un instrumento para mostrar su legitimidad e interés por los problemas sociales; politizando las leyes penales y otorgándoles un carácter mágico que, obviamente, no tienen. Son políticas de final de la cañería, reactivas y no proactivas, vengativas y no preventivas. La aplicación sistemática de estas políticas populistas punitivas va en contra de construir sociedades democráticas avanzadas, formadas por demócratas honestos y solidarios que quieren conseguir que sus esfuerzos personales redunden en el bienestar colectivo y al revés, sabiendo y estando orgullosos de que el estatus social que logren vendrá determinado por su capacidad y esfuerzo personal, no por su ori- 
gen social, etnia, clase o género. La cárcel ha de ser la última ratio, no la primera; la excepción y no la regla.

\section{Referencias bibliográficas}

Antón-Mellón, J., Álvarez, G. y Rothestein, P. (2015) "Medios de comunicación y Populismo punitivo en España: estado de la cuestión", Revista Crítica Penal y Poder, vol. 9, pp. 32-61.

Antón-Mellón, J., Rothestein, P. y Álvarez, G. (2016) "Populismo Punitivo: Discursos que acompañan normas y políticas", en J. García-Borés e I. Rivera (coords.) La cárcel dispar, Barcelona, Edicions Bellaterra.

Antón-Mellón, J., Álvarez, G. y Rothestein, P. (2017) "Populismo punitivo en España (1995-2015): presión mediática y reformas legislativas", Revista Española de Ciencia Política, vol. 43, pp. 3-26.

Barata, F. (2003) "Los mass media y el pensamiento criminológico", en R. Bergalli (coord.) Sistema penal y problemas sociales. Valencia, Tirant lo Blanch, pp. 487-514.

- (1998) "El drama del delito en los mass media", Delito y sociedad: revista de ciencias sociales, vol. 11 y 12, pp. 59-68. Bottoms, A. (1995) "The philosophy and politics of punisment and sentencing" en C. Clarkson y R. Morgan (eds.) The Politics of Sentencing reform, Oxford, Clarendon Press.

Brandariz, J. A. (2016) "Entre la rehabilitación, la incapacitación y el gerencialismo: Tránsitos de retóricas y prácticas del sistema penitenciario español" en J. García-Borés e I- Rivera (coords.) La cárcel dispar, Barcelona, Edicions Bellaterra. Cohen, S. (2002) Folk Devils and Moral Panics [1 ${ }^{a}$. edición, 1972]. Cornwall, Routledge.
Diéz Ripollés, J. L. (2004) "El nuevo modelo de seguridad ciudadana", Revista Electrónica de Ciencia Penal y Criminología, vol. 6, pp. 1-34.

Diéz Ripollés, J. L. (2006) "Algunos rasgos de la delincuencia en España a comienzos del siglo XXI", Revista Española de Investigación Criminológica, núm. 4 (http://www.criminología.net)

Fontana, J. (2011) Por el bien del imperio. Una historia del mundo desde 1945, Barcelona, Pasado y Presente.

Fuentes Osorio, J. L. (2005) "Los medios de comunicación y el Derecho Penal", Revista Electrónica de Derecho Penal y Criminología, vol. 7, pp. 1-51.

García Aran, M. \& Botella Corral, J. (dir.) (2008) Malas noticias, medios de comunicación y garantías procesales en España, Valencia, Tirant lo Blanc.

García Aran, M. (2008) "El discurso mediático sobre la delincuencia y su incidencia en las reformas penales", Revista Catalana de Seguretat Pública, vol. 18. pp. 39-65.

García-Borés, J. (2015) "La cárcel dispar. Indagando la evolución de los telos penitenciarios", Revista Crítica Penal y Poder, vol. 9, pp.146-171.

García-Borés, J. y Rivera, I. (coords.) (2016) La cárcel dispar, Barcelona, Edicions Bellaterra.

Garland, D. (2001) The culture of control, Oxford, Oxford University Press.

Green, P. y Rutherford, A. (2000) Criminal Policy in transition, Oxford, Hart Publishing. Harvey, D. (2007) Breve historia del neoliberalismo, Madrid, Akal.

Hope, T. y Sparks, R. (eds.) (2001) Crime, Risk and insecurity, London, Routledge.

Karstedt, S. y Bussmann, K. D. (eds.) (2000) Social Dynamics of Crime and Control: New Theories for a World in Transition, Oxford, Hart Publishing. 
Kessler, G. (2009) El sentimiento de inseguridad. Sociología del temor al delito. Buenos Aires, Siglo XXI.

Landrove Díaz, G. (2009) El Nuevo Derecho Penal. Valencia, Tirant lo Blanch.

Larrauri, E. (2006) "Populismo punitivo y cómo resistirlo", Revista Jueces para la democracia, vol. 55, pp. 15-22.

Letamendia, F. (2009) Estructura política del mundo del trabajo: fordismo y posfordismo, Madrid, Tecnos.

Lippman, W. (1964) La Opinión pública. [1ª edición, 1922], Buenos aires, Compañía General Fabril Editora.

Maqueda Abreu, M. L. (2003) "Crítica a la reforma penal anunciada", Revista Jueces para la democracia, Información y debate, vol. 47, pp. 6-11.

McCombs, M. \& Shaw, D. (1972) "The agenda-setting functions of mass media", Public Opinion Quarterly, vol. 36, pp. 176-187.

McCombs, M. (2006) Establecimiento de la agenda. El impacto de los medios en la opinión pública y en el conocimiento, Barcelona, Paidós.

Newburn, T. y Jones, T. (2005) "Symbolic politics and penal populism: the long shadow of Willie Horton", Crime, Media, Culture, vol. 1 (I), pp. 72-87.

Nozick, R. (1988) Anarquía, Estado y Utopía, Madrid, F.C.E.

Partido Popular (2008) Programa.

Pavarini, M. (2009) Castigar al enemigo, Quito, FLACSO.

Peres-Neto, L. (2010) Prensa, política criminal y opinión pública: el populismo punitivo en España", Tesina inédita disponible en http://www.tdx.cat/handle/10803/5101

Piketty, T. (2014) Capital in the TwentyFirst Century, Cambridge, Belknap Press.
Pozuelo Pérez, L. (2013) La política criminal mediática. Génesis, desarrollo y costes, Madrid, Marcial Pons.

Pratt, J. et alia (2005) The New Punitiveness: trends, Theories, Perspectives, Devon, William Publishing.

Pratt, J. (2007) Penal Populism, London, Routledge.

Red de Organizaciones Sociales del Entorno Penitenciario (2015). Informe ROSEP 2015, Observatorio del entorno penitenciario.

Roberts, J. et alia (2003) Penal Populism and Public Opinion. Lessons for five countries, New York, Oxford University Press.

Sáez Valcárcel, R. (2002) "La inseguridad, lema de campaña electoral", Revista Jueces para la democracia, Información y debate, vol. 45, pp. 3-8.

Simon, J. (2007) How the War on Crime Transformed American Democracy and Created a Culture of Fear, New York, Oxford University Press.

Soto Navarro, S. (2005) "La influencia de los medios en la percepción social de la delincuencia", Revista Electrónica de Ciencia Penal y Criminología, vol. 7, pp. 1-46.

Stenson, K. y Sullivan, R. R. (eds.) (2001) Crime, Risk and Justice, Cullompton, Willan.

Stiglitz, J. (2012) The Price of Inequality: How Today's Divided Society Endanges Our Future, New York/London, W.W. Norton and Company.

Tonry, M. (2004) Thinking about crime, Oxford, Oxford University Press.

Varona Gómez, D. (2011) "Medios de Comunicación y punitivismo", Revista para el análisis del Derecho, vol. 1, pp. 35-69.

Wacquant, L. (2000) Las cárceles de la miseria, Madrid, Alianza. 
- (2009) Punishing the Poor: the Neoliberal Government of Social Insecurity, Durham, Duke University Press.

Young. J. (2003) The Exclusive Society, London, Sage.

Zolo, D. (2006) Globalización. Un mapa de los problemas, Bilbao, Ediciones Mensajero. 